\title{
Comparison of Equipercentile and Item Response Theory Equating When the Scaling Test Method Is Applied to a Multilevel Achievement Battery
}

\author{
S. E. Phillips \\ Michigan State University
}

Test publishers generally choose an anchor or scaling test approach to the development of a growth scale for a multilevel achievement battery. Although some studies have been conducted comparing traditional equipercentile equating procedures with item response theory models using the anchor test (overlapping items) approach, to date there is no evidence on the comparability of equating procedures when the scaling test approach is used. The purpose of this study was to compare the equipercentile, Rasch, one-parameter modified logistic, and two-parameter logistic item response theory procedures in the equating of a multilevel achievement test battery using the scaling test approach. Since the equipercentile method has been widely used by test publishers, it was chosen as a standard for comparison of the experimental results. Individual item pseudo-guessing parameters were specified for the one-parameter modified logistic and two-parameter logistic item response theory models based on the proportion of students in the national standardization sample selecting the least attractive distractor for the item. Two grades-fourth and eighth - and two subtests - reading and mathematics-were selected for analysis. The results of the study suggest that for a small-sample situation in which the scaling test approach has been applied to a multilevel achievement battery, the one-parameter modified and two-parameter item response theory methods (as modified in this study) appear to be viable alternatives to the equipercentile procedure.

The problem of horizontally and vertically equating test levels has been a measurement issue in

APPLIED PSYCHOLOGICAL MEASUREMENT

Vol. 7, No. 3, Summer 1983, pp. 267-281

(C) Copyright 1983 Applied Psychological Measurement Inc. 0146-6216/83/030267-15\$2.00 achievement testing since the advent of multilevel and multiform batteries. The issue of vertically equating tests of unequal difficulty is of particular concern in the development of growth models that relate student performance on a single test level to an achievement continuum spanning the entire range of grades (e.g., Kindergarten through 12) for which levels of the test have been developed. The purpose of growth scores is to measure achievement across levels on a common score scale so that comparisons can be made across grades from year to year. Mittman (1958) empirically investigated three methods for constructing a growth scale for a multilevel achievement battery. They include the anchor, complete, and scaling test methods.

\section{Scaling Methods}

In the complete test method, student performance on the achievement continuum at a given grade is measured directly by administering all levels of the test to students in that grade. Although this process yields direct estimates of average performance across content levels, it suffers from both practical and technical problems. The required testing time for the number of test levels that must be administered at each grade is prohibitive, students may be unduly frustrated with entire tests of too difficult content, and motivation may be a problem for content that is far too easy. The result is a set of data for which a large proportion of the variance 
may be due to chance (Hieronymus, Lindquist, \& Hoover, 1983).

The anchor test method solves the practical problems of the complete test method but still suffers from technical problems of its own. In the anchor test method the performance of surdents at adjacent grade levels is linked through a set of items common to both levels. This procedure has the advantages that no special tests need be administered at any grade level and that all items of a test level are reasonably appropriate for the grade at which they are administered; at the same time it creates limitations in quantifying growth across levels. Hieronymus et al. (1983) have indicated that this method is not totally satisfactory for achievement test levels of heterogeneous difficulty and content. They cited problems of irregular average growth patterns at given ability levels, especially at the extremes of the score distribution. The authors suggested that these anomalies may have occurred because the linking test (overlapping items) for two successive levels is not representative of the content difficulty of either of the levels. The common item link between any two successive levels contains the most difficult items at the end of the lower level test and the easiest items at the beginning of the upper level test. Morgan (1980) found the equating results in such a sifuation to be unsatisfactory and attributed the poor results to the effects of speededness. A related problem cited by these researchers and others (Cole, Trent, \& Wadell, 1982; Slinde \& Linn, 1978) is the cumulative error introduced when chaining across a series of levels in establishing the extremes of the score scale.

Of the three methods investigated, the scaling test method was found most satisfactory on both practical and technical grounds. In this method, a special scaling test is constructed which contains a few items of appropriate content and difficulty for each of the levels of the test. Unlike the administration of complete test levels, this condensed multilevel test is short enough to be completed in one sitting, requiring each student to respond to fewer items of inappropriate difficulty and content. At the same time, use of a scaling test retains the advantages of administering a common set of items to all grades and of obtaining direct equating data beyond adjacent levels.

From the scaling test results, it is possible to estimate what the average performance of a grade group would be if that grade group were to take any of the other test levels (Cole, 1982). This is of particular importance for out-of-level testing, where a student accelerated or retarded in development may be administered a test level one or two levels above or below the student's current grade placement. In such cases, it is important that the scaled score assigned based on the out-of-level test be comparable to that which would have been assigned if the student had been administered the appropriate on-level test (Hoover, 1982a; Loyd \& Hoover, 1980). As Hoover (1982a) has observed, even if relatively minor errors are present in equating adjacent test levels, they tend to be systematic and cumulative across levels in the chain of equatings. Errors also occur in equating individual regular battery levels of the test to a common scaling test, since the tests are not parallel and may not be unidimensional, but these errors are not additive.

The disadvantages of the scaling test method are similar to but less severe than those of the complete test method: a separate test must be constructed and administered, and student motivation may decline on items of inappropriate difficulty and content. Judging the limitations to be outweighed by the advantages, some test publishers rely entirely or in part on the results of a scaling test administration for vertical equating (Cole et al., 1982; $\mathbf{H i}^{-}$ eronymus et al., 1983 ).

\section{Equating Iprocedures}

Selection of the scaling or anchor test method to obtain data for vertically equating levels of an achievement battery is the first step in the equating process. The second step is the choice of the equating procedure for defining the fractional scores on one test (Level A for the anchor test method or scaling test for the scaling test method) that are equivalent to each integer score on the other test (adjacent Level $\mathrm{B}$ for the anchor test method or regular battery test for the scaling test method). 
Traditionally, the model implemented for the equating of tests of unequal difficulty and content has been some variation of equipercentile or linear equating (Angoff, 1971; Kolen, 1981). Recently, item respose theory ( $\mathbb{R T}$ ) has been recommended as an alternative (Lord, 1980; Wright \& Stone, 1979). Lord (1977) has argued that traditional equating methods are theoretically inappropriate for equating tests of unequal difficulty but that $\mathbb{R T}$ methods are appropriate in such circumstances.

Since Slinde and Linn $(1978,1979)$ indicated a need for more research examining the limitations of appropriateness of the various vertical equating methods, several studies have addressed this issue. A study by Marco, Petersen, and Stewart (1980) has compared the adequacy of several curvilinear equating models for tests of similar and different difficulty based on data from the verbal portion of the Scholastic Aptitude Test (SAT). Loyd and Hoover (1980) reported results related to the vertical equating of mathematics subtests of the Iowa Tests of Basic Skills (ITBS) using the Rasch model. Kolen (1981) reported results of a study comparing $\mathbb{I R T}$ and conventional equating methods for the anchor and complete test methods of scaling an achievement test (Iowa Tests of Educational Development; ITED) having a limited number of levels. Dunbar, Cook, and Eignor (1981) also compared the calibrations provided by different latent trait models.

In general, these studies have found similar results across methods for tests of approximately equal difficulty (horizontal equating) but substantially different results across methods for tests of unequal difficulty (vertical equating). The three-parameter logistic model has generally been found to provide results most similar to the equipercentile method in vertical equating applications, while the Rasch model seems to provide a definition of score scale equivalence that is different from the other methods. Divgi (1981) stated that "the Rasch model is not suitable for vertical equating of multiple choice tests" (p. 203). Traub and Wolfe (1981) provided an overview of the use of $\mathbb{I R T}$ in assessing educational achievement and concluded that poor results may be expected when calibrating multiple- choice items with the Rasch model due to the effects of guessing and speededness.

Other recent studies investigating the choice of IRT models for multiple-choice tests include Hambleton (1983), Holmes and Bogan (1983), Cook and Douglass (1982), Drasgow (1982), Holland and Rubin (1982), Holmes (1982), Hulin, Lissak, and Drasgow (1982), Kolen and Whitney (1982), and Petersen, Cook, and Stocking (in press). Cook and Eignor (1983) investigated the application of IRT methods in equating achievement tests. The general conclusions of the more recent studies support the earlier findings of unsatisfactory Rasch results and the robustness of the three-parameter logistic model for vertical equating but add the condition that for the three-parameter model the number of examinees and items be large. Generally, large samples are defined as at least 1,000 examinees and approximately 60 items; but with the tradeoff in accuracy between the two, some researchers recommend sample sizes of 2,000 for tests with fewer items (Hulin et al., 1982; Lord, 1980). These more recent studies also suggest that the two-parameter logistic model and linear equating methods may provide better results than the three-parameter model when sample sizes are small, although the use of the linear equating method is still questionable, given Kolen's (1981) finding that it was not satisfactory for equating tests of unequal difficulty.

\section{Purpose of the Scady}

The vertical equating studies that have been reported to date relate to scaling and equating multiple-choice examinations that share a common external or internal anchor test. IRT equating procedures have not been studied in scaling designs that use a separate scaling test to vertically equate achievement test levels. The purpose of the present study was to compare traditional and IRT equating procedures when the scaling test method has been applied to a multilevel achievement battery.

A variety of common score scales might be utilized in comparing results. Since it is not the purpose of this study to debate the relative merits of 
the possible scales, one such scale was chosen as the basis for expressing disagreements between equating procedures. That scale was the grade development scale (GDS), a scale somewhat similar to grade equivalents but developed by a different underlying logic (Cole, 1982). This scale was available from the test publisher, and it was felt that the size of the discrepancies expressed on a grade equivalent type scale would have intuitive meaning for many test users. For a comparative study, the choice of scales is arbitrary and does not affect the conclusions.

\section{Methogd}

\section{Test 猶struments}

The achievement test. The 3-R's Test utilized in the present study is a basic skills achievement test battery designed for use in Grades Kindergarten $(\mathbb{K})$ through 12 . There are 11 different levels of the test: Levels 6 through 14 correspond to Grades $\mathbb{K}$ through 8, Level $15 / 16$ to Grades 9 and 10 , and Level $17 / 18$ to Grades 11 and 12 . The test contains three content subtests: reading, language, and mathematics. In Grades $\mathrm{K}$ through 2 there are only two subtests, reading and mathematics, and these contain approximately 30 items each. Students are allowed 35 to 40 minutes to work on each subtest and mark their answers in machine-scorable test booklets. In Grades 3 through 12, the reading, language, and mathematics subtests consist of 50,40 , and 35 items, respectively, with 30 to 40 minutes of working time alloted per subtest. Students in Grades 3 through 12 record their answers on separate machine-scorable answer sheets.

National norms for the test were based on a probability sample of approximately 8,000 students per grade in Grades $\mathbb{K}$ through 12. Participating public and parochial school districts were randomly sampled from listings compiled from census data based on geographic location and district size. Additional information on the content specifications, item development, and national standardization of the test can be obtained from the technical manual (Cole et al., 1982).
The scaling test. The scaling test in each content area consisted of a sample of representative items across grade levels. As administered to Grades 4 though 12 , the scaling test included content across Grades 1 through 12 in reading and Grades 4 through 12 in mathematics. All of the scaling test items were different from all items in the regular battery rests. Preceding the spring standardization of the regular battery tests, a subsample of participating schools was selected to administer the scaling test forms. Approximately 500 students per grade participated in the scaling test study.

In Grades 4 through 12 , the mathematics scaling test consisted of 68 four-choice multiple-choice items and the reading scaling test consisted of 63 fourchoice multiple-choice items. Each was administered in a 50-minute time period, which was sufficient for almost all students to attempt every irem. In cases where elementary students were asked to respond to high school level content, the test instructions clearly stated that students were not expected to be able to answer all the items, that some items would be too difficult, and that the student should omit difficult items or return to them later if time permitted.

\section{Equating Models}

Four equating procedures were chosen for comparison in this study: the equipercentile, Rasch, one-parameter modified logistic, and two-parameter logistic models. The choice was based both on popularity and on appropriateness with small samples.

The equating comparisons in this study were based on final samples of 300 to 500 valid records of students who had taken both the scaling and regular battery tests. The relacively small sample sizes occurred because use of the scaling test method requires a special test administration apart from the national norming of the test. Sampling and cost considerations often prohibit publishers from using larger samples in a scaling study.

Based on Lord's (1980) recommendations, the sample sizes in the present study were judged too small for stable estimation with the three-parameter 
model. The one-parameter modified logistic and two-parameter logistic models were considered promising alternatives, given the findings of Hulin et al. (1982), which indicated that the two-parameter model may be adequate for some purposes with as few as 30 test items and 500 examinees.

The Rasch model has also been recommended for use with small samples (Wright \& Stone, 1979), although the research literature on equating with the Rasch model is conflicting (see, e.g., Divgi, 1981; Guskey, 1981; Loyd \& Hoover, 1980; Rentz \& Bashaw, 1978). In addition, the Rasch model has been used in the equating of other standardized achievement tests (Lenke \& Rentz, 1982).

For the modified one-parameter model, as described by Kolen (1981), an average item discrimination parameter is specified. This sets all item characteristic curve (ICC) slopes equal for a single test, as does the Rasch model, but allows the flexibility of having a different common siope for each of the rests to be equated. The average biserial correlation calculated from the item biserial correlations provided by a standard item analysis program was used to specify the average item discrimination parameter for each test and ranged in value from .40 to .63. Lord (1980) described an approximate relationship between the IRT discrimination parameter and the biserial correlation, given the assumption of no guessing. Due to the specification of nonzero lower asymptotes in the present study, Lord's approximation was considered inappropriate.

\section{Gressing}

A major issue in the application of IRT involves the estimation of the lower asymptote ( $c$ parameter) of the ICC. The $c$ parameter represents the probability of a correct response for a student of very low ability. For multiple-choice items, students who do not know the answer may select the correct response by guessing. This implies that even at very low levels of ability, the probability of success is greater than zero. The three-parameter logistic model, for which results to date have been encouraging, includes the estimation of a lower asymptote. The two-parameter logistic, one-parameter modified logistic, and Rasch models assume that the lower asymptotes for all items are zero. This has not generally been considered a tenable assumption for multiple-choice tests (Traub \& Wolfe, 1981), but small samples may still preclude the use of the three-parameter logistic model.

Haebara (1981) and Choppin (1983) have experimented with the inclusion of a "guessing" parameter as a fixed constant for each item in the two-parameter logistic and Rasch models. Haebara (1981) estimated these constants from the responses of low scoring minority groups; Choppin (1983) based the lower asymptote on the splicing of a logistic function for guessing (maximum value at the reciprocal of the number of answer choices) with the estimated Rasch function. The present study considered an alternative approach for estimating fixed constants for the lower asymptotes of the ICCs.

The reciprocal of the number of answer choices represents the probability of choosing a response completely at random. Hoover (1982b) suggested that students responding to achievement test items do not choose randomly among the alternatives. Lord (1977) noted that skilled item writers will produce distractors that are particularly attractive to examinees who do not know the correct answer to an item, thus reducing the probability of guessing correctly. Thorndike (1982) cited differing proportions of students choosing item distractors as evidence that students who do not know the answer to an achievement test item do not guess completely at random. Norton (1950) demonstrated that the proportion of students choosing the least attractive distractor for an item is an estimate of the maximum proportion of students answering the item correctly by random guessing. This conclusion is based on the assumption that the group of students who are randomly guessing should choose the response options in equal proportions.

Consistent with the conclusions of Hoover (1982b), Thorndike (1982), and Lord (1977), the Norton estimates of the probability of success due to guessing are greater than zero but less than the reciprocal of the number of options for achieve- 
ment test data (Cole et al., 1982; Hieronymus et al., 1983). Although the lower asymptotes estimated by the Norton method could be expected to be group dependent, the Norton procedure has the following advantages: it utilizes data routinely obtained during the norming process, it may provide more accurate estimation of the guessing behavior of students on achievement tests, and it makes the use of a three-parameter model possible when sample sizes in a scaling test administration are too small for direct estimation of the $c$ parameter with maximum likelihood procedures. In large norming samples, the Norton estimates could be expected to be relatively stable.

The Norton method was used in the present study to estimate fixed constants for the item lower asymptotes for the one-parameter modified logistic and two-parameter logistic models. Other item parameters were then estimated by maximum likelihood procedures conditioned on the fixed $c$ parameters. Standard item analyses from the norming sample provided the proportions used in fixing the lower asymptotes, and the specified values ranged from 01 to .17. To distinguish this application of IRT models with fixed lower asymptotes, the labels "one-parameter double-modified" and "two-parameter modified" have been adopted throughout the rest of this paper.

\section{Subtests and Grades}

Two unlike subtests, reading and mathematics, and two widely-spaced grade levels, fourth and eighth, were selected for analysis. These grades and subtests were chosen to represent different degrees of unidimensionality and variability.

Cook, Dorans, Eignor, and Petersen (1983) investigated the relationship between unidimensionality and the quality of IRT true-score equating for the verbal and mathematics subtests of the SAT. They found the mathematics items to be more nearly unidimensional and to have equating results superior to the verbal items. In an earlier study, Loyd and Hoover (1980) had suggested multidimensionality as a possible cause for the invalidity of the Rasch model for vertically equating the ITBS mathematics computation test. This finding for an achievement test may be related to the general notion that students may improve their reading skills through independent reading, whereas the ability to perform a mathematical operation may be closely tied to whether the operation has been taught in the school curriculum (Lenke \& Rentz, 1982). For the present study, these results suggested that the reading subtest could be expected to be more unidimensional than the mathematics subtest and to fare better in the IRT comparisons (Thorndike, 1982).

Wright (1980) has argued that more accurate measurement is possible when the ability of a student is within one logit (unit of ability and item difficulty in the Rasch model) of the average difficulty of the items. Since within-grade achievement variability increases as students attend school for a longer period of years, it was hypothesized that results for the more homogeneous fourth-grade group would differ from those of the more heterogenous eighth-grade group (Thorndike, 1982).

\section{Irem and Ability Calibrations}

The maximum likelihood parameter estimates for the one-parameter double-modified logistic model and the two-parameter modified logistic model were obtained from the LOGIST computer program developed by Wood, Wingersky, and Lord (1976). In order to allow for unequal average discrimination parameters for the scaling and regular tests in the one-parameter modified model, separate estimation was necessary. To provide comparability of procedures across equatings, parameters were estimated separately for each test for all equating methods. This decision might also represent the procedure of choice for a publisher unwilling to assume the additional programming burden of matching and merging the student responses from the two test administrations and increasing the program array sizes, both of which would be necessary to implement a combined estimation procedure. In all LOGIST calibrations, ability estimates were scaled to have a mean of zero and a standard deviation of one.

Rasch model estimates were obtained from BICAL (Wright \& Mead, 1976). Misfitting persons 
were deleted based on the mean square person fit statistic provided in the program. The program default value of 2.0 was used to identify unusual values of the person fit statistic. The motivation for deleting misfitting persons is explicated by Wright and Stone (1979) and Ryan (1980), who described misfitting persons as exhibiting response patterns which suggest that the test did not accurately measure their abilities. Ryan (1980) also claimed that a larger number of items will fit the Rasch model when misfitting persons have been deleted. In this study the percentage of deleted subjects varied from a minimum of $1 \%$ to a maximum of $7 \%$.

With the decision to estimate item parameters for each test separately, it was not possible to ensure that BICAL would delete the same persons each time. Thus, the remaining groups whose parameter estimates were used in the equating process were not strictly equal in ability. Their elimination can be justified in part on the basis that they were not adequately measured by the test and therefore were contributing random error to the results. Since the number of persons deleted. was small in most cases, the equating was probably not substantially affected by this decision.

\section{Equating Procedures}

Equipercentile. The traditional equipercentile method for linking scaling and regular battery test performance is typically applied as follows. Based on the common sample of students, a raw score frequency distribution and associated percentile ranks are obtained for both the scaling test and its corresponding regular battery subtest at a given grade. The ogives corresponding to these data for each test are plotted and smoothed. Scores (or fractional scores) having identical percentile ranks in the smoothed cumulative distributions of both the scaling and regular tests are considered equivalent. A conversion table of such equivalences is prepared, which relates every raw score on the regular battery subtest to its equivalent score on the corresponding scaling test form.

IRT. The procedure for the $\mathbb{R} T$ equating of the scaling and regular tests followed the logistic truescore equating method outlined by Lord (1980).
The method is based on the assumption of equal ability distributions.

Assume two tests ( $i=1,2)$, each composed of $n_{i}$ items which have been administered to the same students (or randomly comparable groups). Let the item difficulty, discrimination, and lower asymptote parameters be denoted by $a_{i j}, b_{i j}$, and $c_{i j}$, respectively, $i=1,2 ; j=1, \ldots, n_{i}$, and $D$ be an arbitrary scaling constant equal to 1.7. The number-correct true scores $\left(\xi_{i}\right)$ of Tests 1 and 2 are related to ability $(\theta)$ by their test characteristic curves $\left[P_{i}(\theta)\right]$ if both tests measure the same ability. The relationship is as follows for test $i$ :

$$
\begin{aligned}
\xi_{i} & =P_{i}(\theta) \\
& =\Sigma c_{i j}+\Sigma\left(1-c_{i j}\right) \frac{\exp \left[D a_{i j}\left(\theta-b_{i j}\right)\right]}{1+\exp \left[D a_{i j}\left(\theta-b_{i j}\right)\right]} .
\end{aligned}
$$

To equate Test 2 (regular battery) to Test 1 (scaling), $\theta$ must be eliminated from the equations for $\xi_{1}$ and $\xi_{2}$. This is accomplished by substituting arbitrary values of $\theta$ into $P_{2}(\theta)$ until $\theta$ values are found which correspond to integer values of $\xi_{2}$. The $\theta$ values which generate the $\xi_{2}$ integer true scores are then substituted into the equation for $P_{1}(\theta)$ to calculate the corresponding $\xi_{1}$ fractional true scores. The computer program LOGTRUE (Phillips \& Anderson, 1983) was used for this part of the analysis.

When the lower asymptotes $\left(c_{i j}\right)$ are nonzero, the true-score equating procedure does not yield equated scores below the sum of the $c_{i j}$ parameters. To determine equated scores below this point, an extrapolation procedure is required (e.g., see Cook \& Douglass, 1982; Kolen, 1981; Lord, 1980). However, such a procedure is somewhat arbitrary and is not a function of the particular IRT model used in the equating. Thus, the comparisons of the present study were limited to equated true scores which could be calculated directly from each logistic model.

The Rasch model parameters estimated by BICAL are scaled so that the mean difficulty of the test is zero. Since the common basis for equating in this study was groups of persons rather than overlapping items, the item difficulty parameters had to be adjusted so that the mean of the ability estimates for the two tests being equated would be the same. The result of this adjustment process was 
to move the difficulty estimates for the two tests apart on the scale in proportion to the difference in ability estimates obtained when each test was centered at zero difficulty. Wright and Stone (1979) have described the common person equating procedure utilized in this study.

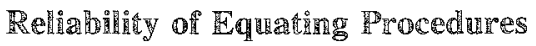

To determine whether the equating differences between any two methods were greater than expected by chance, it was necessary to estimate the amount of error associated with each method. To estimate error, a reliability study was conducted. The study employed two random samples of 500 students each, selected from the national norming sample for Grade 4 and Grade 8.

Each equating method was applied to the pair of random samples at each grade level. For example, in Grade 4, the mathematics subtest was equated to itself based on the two independent random samples selected from all fourth graders in the national norming sample. Were it not for errors of measurement and sampling errors in the selection of individuals, these pairs of random samples should have given identical results. That is, it would be expected that a score of 30 on the mathematics test in one sample would be equated to a score of 30 in the other sample. The degree to which this or any other score in the one sample was not equated to the same score in the other sample provided an estimate of the errors associated with the equating procedure. For comparison on a common metric, these differences were expressed in terms of the GDS scale. This procedure of estimating error by equating a test to itself is similar to that utilized by Marco, Petersen, and Stewart (1980) and by Loyd and Hoover (1980).

Strictly speaking, use of random samples did not provide the equal ability groups required for the true-score equating procedure and for comparison with the experimental groups in which the same persons took both tests. However, due to memory and practice effects, it was felt that the administration of the same test twice to a group of examinees would underestimate the measurement errors associated with the replication of methods. The reliability procedure used in the study may still have underestimated equating error, since it was based on equating tests of equal difficulty rather than tests of unequal difficulty and because the equating was not done through a scaling test.

\section{Croiterion Variable}

The statistic used for comparison in this study was the mean absolute difference between GDS scores. For the reliability data this statistic was the average absolute difference between GDS scores assigned in each random sample by equating the test to itself. For the experimental study the average absolute difference was computed by finding the average of the absolute differences between GDS scores assigned to each regular battery raw score by any two of the equating procedures.

\section{Results}

The GDS mean absolute differences for the reliability and experimental results are summarized in Table 1. Results are presented separately for each subject and grade combination. Reliability results are shown in parentheses along the diagonals.

In Table 1, mean absolute differences marked with an asterisk were considered "significant." In the present context, a "significant mean difference" between methods is one that exceeds both of the corresponding mean differences found in the reliability study. For example, for the equipercentile and Rasch equating procedures in Grade 4 math, the between-methods difference was .1100 . It is starred since it exceeds the reliability mean differences of .0094 and .0188 for the equipercentile and Rasch procedures, respectively.

Except for the Rasch results in Grade 4 reading, all of the mean absolute differences were of approximately the same order of magnitude with a maximum close to. 1 . In the Grade 4 reading test, the Rasch grade development scores, on the average, were 3 months different from the values for the equipercentile results. In contrast to the discrepant results of the Rasch analysis in Grade 4 reading, both the one-parameter double-modified logistic and two-parameter modified logistic meth- 
Table 1

Mean Absolute Differences In GDS Units By

Method For The Reliability And Experimental Studies

\begin{tabular}{|c|c|c|c|c|}
\hline $\begin{array}{r}\text { Grade, Test } \\
\text { and Method } \\
\end{array}$ & EQUIPER & RASCH & LOGIPM & LOG2PM \\
\hline \multicolumn{5}{|l|}{ Grade 4 Math } \\
\hline EQUTPER & $(.0094)^{a}$ & $.1100^{*}$ & $.1167 *$ & $.1000 \%$ \\
\hline RASCH & & $(.0188)$ & $.1433 \%$ & $.1333 *$ \\
\hline LOGIPM & & & $(.0000)$ & .0300 \\
\hline LOG2PM & & & & $(.0375)$ \\
\hline \multicolumn{5}{|l|}{ Grade 4 Reading } \\
\hline EQUIPER & $(.0404)$ & $.2911^{*}$ & $.0956 \%$ & $.1156 \%$ \\
\hline RASCH & & $(.0000)$ & $.2644 *$ & $.2778 *$ \\
\hline LOG1PM & & & $(.0489)$ & .0244 \\
\hline LOG2PM & & & & $(.0340)$ \\
\hline \multicolumn{5}{|l|}{ Grade 8 Math } \\
\hline EQUIPER & $(.0719)$ & $.0813 *$ & $.1031^{*}$ & .0688 \\
\hline RASCH & & $(.0000)$ & $.0594 *$ & $.0688^{*}$ \\
\hline LOG1PM & & & $(.0000)$ & $.0781^{*}$ \\
\hline LOG2PM & & & & $(.0313)$ \\
\hline \multicolumn{5}{|l|}{ Grade 8 Reading } \\
\hline EQUIPER & $(.0766)$ & $.1000 *$ & .0745 & .0532 \\
\hline RASCH & & $(.0979)$ & .1021 & $.1106 \%$ \\
\hline LOGIPM & & & $(.1106)$ & .0426 \\
\hline LOG2PM & & & & $(.1085)$ \\
\hline
\end{tabular}

ods provided results quite consistent with the equipercentile method over all grade/subject combinations. On the average, the two logistic methods deviated from the equipercentile method by onetenth of a grade development score point for all grade/subject combinations. Overall, the two-parameter modified logistic analyses provided slightly closer results to the equipercentile method than did the one-parameter double-modified logistic analyses. Both logistic methods were more consistent between grades and between subjects than the Rasch results.

Since the equating of each regular battery test to its corresponding scaling test was based on comparable groups of examinees, sampling error associated with students can probably be ruled out as a factor in explaining the differences in the end results. It appears that the equating methods represent different definitions of score-to-score equivalence. It may be informative to consider the most inconsistent pair of methods, equipercentile and Rasch, for the most deviant test, Grade 4 reading.

Scaling test raw scores and their regular battery equivalents, as determined by the Rasch and equipercentile methods for the Grade 4 reading test, are presented in Table 2. The ability scores listed in the first column were derived from the Rasch model analysis. The discrepancies between the end results of these two methods are noticeable. A scal. ing test score of 43 (out of 63) has a Rasch equivalent on the regular battery test of 41 (out of 50 ). It has an equipercentile equivalent of 44 . A scaling 
Table 2

Regular Battery Raw Scores Equated to Scaling

Test Raw Scores via the Rasch and

Equipercentile Methods for Reading Grade Four

\begin{tabular}{|c|c|c|c|c|}
\hline \multirow[b]{2}{*}{ Abilities } & \multirow[b]{2}{*}{ GDS } & \multirow[b]{2}{*}{$\begin{array}{c}\text { Scaling Test } \\
\text { Raw Scores }\end{array}$} & \multicolumn{2}{|c|}{ Regular Battery } \\
\hline & & & $\begin{array}{c}\text { Rasch } \\
\text { Equivalences }\end{array}$ & $\begin{array}{l}\text { Equipercentile } \\
\text { Equivalences }\end{array}$ \\
\hline 4.01 & 7.3 & 60.0 & 49 & \\
\hline 3.27 & 7.2 & 57.2 & 48 & \\
\hline 2.82 & 7.1 & 54.8 & 47 & \\
\hline 2.49 & 7.1 & 52.5 & 46 & 49 \\
\hline 2.22 & 7.0 & 50.4 & 45 & 48 \\
\hline 1.99 & 6.8 & 48.4 & 44 & 47 \\
\hline 1.80 & 6.5 & 46.6 & 43 & 46 \\
\hline 1.62 & 6.3 & 44.8 & 42 & 45 \\
\hline 1.46 & 6.1 & 43.2 & 41 & 44 \\
\hline 1.31 & 5.9 & 41.6 & 40 & 43 \\
\hline 1.17 & 5.7 & 40.2 & 39 & 42 \\
\hline 1.04 & 5.5 & 38.8 & 38 & 41 \\
\hline 0.91 & 5.2 & 37.4 & 37 & 39,40 \\
\hline 0.80 & 5.0 & 36.1 & 36 & 37,38 \\
\hline 0.68 & 4.7 & 34.8 & 35 & 36 \\
\hline 0.57 & 4.6 & 33.6 & 34 & 34,35 \\
\hline 0.46 & 4.4 & 32.5 & 33 & 32,33 \\
\hline 0.36 & 4.2 & 31.3 & 32 & 31 \\
\hline 0.26 & 4.1 & 30.2 & 31 & 30 \\
\hline 0.16 & 4.0 & 29.2 & 30 & 28,29 \\
\hline 0.06 & 3.9 & 28.1 & 29 & 27 \\
\hline-0.04 & 3.8 & 27.1 & 28 & $24,25,26$ \\
\hline-0.13 & 3.6 & 26.1 & 27 & 22,23 \\
\hline-0.23 & 3.5 & 25.2 & 26 & 21 \\
\hline-0.32 & 3.4 & 24.2 & 25 & 20 \\
\hline-0.42 & 3.3 & 23.3 & 24 & 19 \\
\hline-0.51 & 3.3 & 22.4 & 23 & 18 \\
\hline-0.61 & 3.2 & 21.5 & 22 & 16,17 \\
\hline-0.71 & 3.0 & 20.6 & 21 & 15 \\
\hline-0.80 & 3.0 & 19.7 & 20 & \\
\hline-0.90 & 3.0 & 18.9 & 19 & 14 \\
\hline-1.00 & 2.9 & 18.0 & 18 & 13 \\
\hline-1.10 & 2.9 & 17.2 & 17 & \\
\hline-1.21 & 2.8 & 16.3 & 16 & 12 \\
\hline-1.32 & 2.8 & 15.5 & 15 & \\
\hline-1.43 & 2.7 & 14.7 & 14 & 11 \\
\hline-1.54 & 2.7 & 13.8 & 13 & 10 \\
\hline-1.66 & 2.6 & 13.0 & 12 & 9 \\
\hline-1.79 & 2.6 & 12.1 & 11 & 8 \\
\hline-1.92 & 2.6 & 11.3 & 10 & \\
\hline-2.07 & 2.5 & 10.4 & 9 & 7 \\
\hline-2.22 & 2.5 & 9.5 & 8 & \\
\hline-2.39 & 2.5 & 8.6 & 7 & 6 \\
\hline-2.58 & 2.5 & 7.7 & 6 & \\
\hline-2.80 & 2.5 & 6.7 & 5 & \\
\hline-3.06 & 2.5 & 5.7 & 4 & 5 \\
\hline-3.38 & 2.5 & 4.6 & 3 & 4 \\
\hline-3.82 & 2.5 & 3.4 & 2 & 3 \\
\hline-4.55 & 2.5 & 2.0 & 1 & 1,2 \\
\hline
\end{tabular}

Downloaded from the Digital Conservancy at the University of Minnesota, http://purl.umn.edu/93227. May be reproduced with no cost by students and faculty for academic use. Non-academic reproduction requires payment of royalties through the Copyright Clearance Center, http://www.copyright.com/ 
test score of 25 has a Rasch equivalent on the regular battery test of 26 and an equipercentile equivalent of 21 . Differences of 3 to 4 raw score points are prevalent in the extremes of the scaling test scores. Only in the middle of the distribution do the raw score differences become as small as one point. In terms of grade development scaled scores, the Rasch values were as much as 7 months higher than the equipercentile results in the upper portions of the raw score scale. In contrast, the discrepancies between the equipercentile and other logistic model results were rarely more than 1 or 2 months and never more than 3 months at any point on the score scale.

\section{Discussion}

To appreciate the magnitude of the differences shown in Table 2, consider the instructional implications for a classroom teacher. Presume a student has made a raw score of 44 on the regular fourth-grade reading test. In the national norming sample, this score corresponds to a percentile rank of 91.2 among fourth-grade students. Clearly, this is a high score and it might be expected that the student's reading teacher would prescribe materials well above average in sophistication. From Table 2 , the GDS score assigned to a raw score of 44 by the equipercentile equating procedure is 6.1 . Based on this GDS score, the teacher might prescribe reading materials for this student that are at the lower end of the sixth-grade range. ${ }^{1}$ On the other hand, for the same raw score, a GDS score equivalent of 6.8 is given in Table 2 for the Rasch equating procedure. Using this higher GDS score, it might be expected that the teacher would prescribe instructional materials on a par with those handled by a sixth-grade student at the end of the school year. Thus, the equated GDS scores for the equipercentile and Rasch procedures seem to suggest somewhat different prescriptions for the appropriate level of reading materials for this student.

A discrepancy of this sort is particularly relevant to the present test battery because its grade devel-

'See Cole (1982) for the rationale supporting the use of GDS scores as instructional indicators. opment scale was designed specifically to provide information regarding the appropriate instructional level for a student. Whether a difference between 6.1 and 6.8 should call for different choices of materials may be debated. Some teachers would reach different decisions about fourth-grade students with these GDS values; others would not. If the errors of measurement involved in the two equating procedures were to magnify the difference another tenth or two-tenths, different prescriptions would probably be reached by most teachers. This would be a meaningful difference, since a student who is actually at an early sixth-grade level of reading ability might become frustrated at being given end-of-sixth-grade materials that are too difficult. On the other hand, a teacher is likely to use the same instructional materials for a student obtaining a GDS of 6.0 or 6.2 , the magnitude of difference common in the one- and two-parameter modified logistic models.

The results of this study utilizing the scaling test method are consistent with the Slinde and Linn (1979), Loyd and Hoover (1980), Kolen (1981), Divgi (1981), and Holmes (1982) anchor test method studies that found the Rasch model unsatisfactory for vertically equating tests of unequal difficulty. Kolen (1981) suggested that the poor results obtained for both the Rasch and one-parameter modified equating procedures in his study may have resulted from failure of the models to take guessing into account. Although in the present study the Rasch results were inconsistent across applications, the one-parameter double-modified (and the twoparameter modified) logistic models (which included pseudo-guessing parameters) consistently provided results that were reasonably close to those obtained with the equipercentile equating procedure. Yen (1980) suggested that for difficult items where guessing is a factor, a two-parameter $1 \mathrm{CC}$ will compensate with a flatter slope, resulting in negatively correlated difficulty and discrimination parameters. In the present study the correlations between the discrimination fit index and difficulty ranged from -.56 to .05 for the Rasch model, further supporting the possibility that the unfavorable Rasch equating results were due to guessing (Gustafsson, 1979). 
Holmes (1982) observed that the unsatisfactory results of vertical equatings with the Rasch model may be due in part to lack of fit of items to the model and to the lack of unidimensionality. In the present study, using the total fit statistic of the BICAL program, which summarizes overall item fit across students, and a critical value of 2.0 , as suggested in the program manual (Wright \& Mead, 1976 ), $3 \%$ to $10 \%$ of the scaling and $3 \%$ to $16 \%$ of the regular test items were found to misfit. However, even though the reading tests tended to have more misfitting items than the math tests, this did not explain the poor equating results for the Rasch model in Grade 4, since the reading tests in both grades had approximately the same number of misfitting items. ${ }^{2}$

In terms of unidimensionality, the Rasch model fared worse for the subtest assumed to be more unidimensional, reading, in the least variable grade, Grade 4, whereas the two-parameter modified and one-parameter double-modified models, which also assume unidimensionality of the data, performed about equally well for both grades and both subjects. Bogan and Yen (1983) and Cook et. al. (1983) have argued that $\mathbb{R} T$ equating appears to be robust to violations of the unidimensionality assumption, although Cook and Eignor (1983) have indicated the need for developing more precise methods for assessing unidimensionality. Thus, it appears that the guessing problem may be the more serious issue in the choice of models for IRT vertical equating.

The extremes of difficulty present in the scaling test items may have been a factor contributing to the difference in results between the Rasch and equipercentile equating procedures. For a very easy or very difficult test item, the Rasch model approximates the ICC from a limited amount of data at the top or the bottom of the curve, based on the estimation of only one parameter for the curve; most of the curve is an extrapolation. Considerable

\footnotetext{
${ }^{2}$ Once an achievement test battery has been standardized, the items on all forms are fixed until the test is revised and renormed several years later. Thus, it is inappropriate to delete misfitting items in the equating process, since such items will remain on the test when it is subsequently administered by school district customers.
}

error might be expected in the difficulty estimates for such items. With a substantial number of easy or difficult items in a scaling test, it may be hypothesized that this error cumulates and is incorporated into the rest characteristic curve. Such cumulated error might well have a disturbing effect on the equating process.

\section{Conchusions}

For a small-sample equating situation in which the scaling test method has been applied to a multilevel achievement battery (i.e., where the tests being equated are of unequal difficulty, length, and content), the one-parameter double-modified logistic and the two-parameter modified logistic truescore equating procedures appear to be viable alternatives to the equipercentile procedure. Assuming that the results of the equipercentile procedure are an appropriate standard, the Rasch procedure is not recommended for use in this situation.

It should be noted that the results of this study show only that the equated GDS scores based on the $\mathbb{R}$ asch and equipercentile equated score scales are different. No claim is made as to which presents a more accurate assessment of the examinee. Kolen and Whitney (1982) commented on the need for an external criterion for comparing equating methods. Their cross-validation method is one possibility, as is the conditional $p$ value method proposed by Lenke and Rentz (1982); but neither of these methods directly addresses the issue of appropriate instructional level. A study of the relationship between instructional level and the GDS scores assigned by each equating procedure is needed to establish which scale provides the "better" definition of appropriate instructional level.

The $\mathbb{R T}$ equating procedures of the present study placed item parameter estimates on the same scale by equating ability means and standard deviations for separate scaling and regular test calibrations on the same group of students. A more exact weighted least squares procedure for equating ability scales has been proposed by Haebara (1982). Another possibility would have been to use simultaneous estimation procedures to obtain the estimated abil- 
ity parameters from the responses to both scaling and regular test items and then to fix the $\theta$ s while separately estimating the item parameters for the scaling and regular tests. Alternatively, the scaling test items could have been calibrated with all grades combined and then the estimated abilities fixed, while the regular test parameters were estimated within each grade group. Better results might have been obtained in the present study if the item and ability parameters for the scaling and regular tests had been estimated simultaneously, although such a procedure would have precluded the inclusion of the one-parameter double-modified model. Somewhat different results might also have been obtained if misfitting students had not been deleted in the Rasch model calibrations.

The sample sizes utilized in this study are typical of the amount of data a publisher is usually able to obtain. With larger sample sizes or other kinds of achievement tests, the results may differ from those presented here. In the present study, the Norton methodology for specifying pseudo-guessing parameters with the one-parameter modified logistic and two-parameter logistic models appeared promising for situations where sample sizes are too small for estimation with the full three-parameter model. Another promising alternative cited by Cook and Douglass (1982) is the improved lower asymptote estimation capabilities of the new version of LOGIST (Wingersky, Barton, \& Lord, 1982). The research of Choppin (1983) in estimating guessing with the Rasch model and of Swaminathan and Gifford (1982) in using Bayesian estimation in the Rasch model also holds promise for improved IRT results with small sample sizes.

In addition, achievement tests often assess many separate skills in one subtest. Cook and Eignor (1983) indicated the need for developing more precise methods for assessing multidimensionality in achievement tests. The work of McKinley and Reckase (1982) and McKinley (1983) on multidimensional Rasch and two-parameter IRT models may provide improved results in this application.

Finally, the development of common score scales across levels of achievement test batteries is very important to the teachers and administrators who use these scales to chart student growth. Despite its limitations, the scaling test method appears to provide more comprehensive information than the anchor test method for growth scale development. Although the present study utilizing the scaling test method seemed to provide equating results consistent with other studies that employed the anchor test method, continued research with both types of scaling methods is needed to determine the most effective strategies for constructing growth scales in the development of multilevel achievement test batteries.

\section{References}

Angoff, W. H. Scales, norms, and equivalent scores. In R. L. Thorndike (Ed.), Educational Measurement (2nd ed.). Washington DC: American Council on Education, 1971.

Bogan, E. D., \& Yen, W. M. Detecting multidimensionality and examining its effects on vertical equating with the three-parameter logistic model. Paper presented at the American Educational Research Association annual meeting, Montreal, April 1983.

Choppin, B. H. Removing the effects of guessing from latent trait measures. Paper presented at the American Educational Research Association annual meeting, Montreal, April 1983.

Cole, N. S. Grade equivalent scores: To GE or not to $G E$. Division D Vice Presidential Address at the American Educational Research Association annual meeting, New York City, March 1982.

Cole, N. S., Trent, E. R., \& Wadell, D. C. The 3-R's Test technical manual. Achievement edition (Grades $\mathrm{K}-12$ ). Chicago IL: Riverside Publishing Company, 1982.

Cook, L. L., Dorans, N. J., Eignor, D. R., \& Petersen, N. S. An assessment of the relationship between the assumption of unidimensionality and the quality of IRT true-score equating. Paper presented at the American Educational Research Association annual meeting, Montreal, April 1983.

Cook, L. L., \& Douglass, J. B. Analysis of fit and vertical equating with the three-parameter model. Paper presented at the American Educational Research Association annual meeting, New York City, March 1982.

Cook, L. L., \& Eignor, D. R. An investigation of the feasibility of applying item response theory to equate achievement tests. Paper presented at the American Educational Research Association annual meeting, Montreal, April 1983.

Divgi, D. R. Model-free evaluation of equating and scaling. Applied Psychological Measurement, 1981, 5, 203-208 
Drasgow, F. Choice of test model for appropriateness measurement. Applied Psychological Measurement, 1982, 6, 297-308.

Dunbar, S. B., Cook, L. L., \& Eignor, D. R. Item response theory equating: a flexible alternative to conventional methods for solving practical equating problems. Paper presented at the American Educational Research Association annual meeting, Los Angeles, April 1981.

Guskey, T. R. Comparison of a Rasch model scale and the grade equivalent scale for vertical equating of test scores: Applied Psychological Measurement, 1981, 5, 187-201.

Gustafsson, J. E. Testing and obtaining fit of data to the Rasch model. British Journal of Mathematical and Statistical Psychology, 1980, 33, 205-233.

Haebara, T. A method for investigating item bias using Birnbaum's three-parameter logistic model. (Iowa Testing Programs Occasional Papers No. 25) Iowa City: University of Iowa, December 1979.

Haebara, T. Some comments on Noguchi's ability scale equating method. Memoirs of the Faculty of Education, Niigata University, 1982, 24 (No. 1).

Hambleton, R. K. (Ed.). Applications of item reponse theory. Vancouver BC: Educational Research Institute of British Columbia, 1983.

Hieronymus, A. N., Lindquist, E. F., \& Hoover, H. D. Iowa Tests of Basic Skills manual for administrators, supervisors and counselors. Chicago IL: Riverside Publishing Company, 1983.

Holland, P. W., \& Rubin, D. B. (Eds.) Test equating. New York: Academic Press, 1982.

Holmes, S. E. Unidimensionality and vertical equating with the Rasch model. Journal of Educational Measurement, 1982, 19, 139-147.

Holmes, S. E., \& Bogan, E. D. An empirical study of vertical equating methods using the three-parameter logistic model. Paper presented at the American Educational Research Association annual meeting, Montreal, April 1983.

Hoover, H. D. Some comments on vertical equating using item response theory. Paper presented in a symposium on advances in item response theory at the American Educational Research Association annual meeting, New York City, March 1982. (a)

Hoover, H. D. Personal communication, University of Iowa, January 1982. (b)

Hulin, C. L., Lissak, R. I., \& Drasgow, F. Recovery of two-and three-parameter logistic item characteristic curves: A monte carlo study. Applied Psychological Measurement 1982, 6, 249-260.

Kolen, M. J. Comparison of traditional and latent trait theory methods for equating tests. Journal of Educational Measurement, 1981, 18, 1-11.

Kolen, M. J., \& Whitney, D. R. Comparison of four procedures for equating the tests of general educa- tional development. Journal of Educational Measurement, 1982, 19, 279-293.

Lenke, J. M., \& Rentz, R. R. The use of the Rasch model in the development of the Stanford Achievement Test. Paper presented at the National Council on Measurement in Education annual meeting, New York City, March 1982.

Lord, F. M. A study of item bias using item characteristic curve theory. In Y. H. Poortinga (Ed.), Basic problems in cross-cultural psychology. Amsterdam: Swets \& Zeitlinger B. V., 1977.

Lord, F. M. Application of item response theory to practical testing problems. Hillsdale NJ: Erlbaum, 1980.

Loyd, B. H., \& Hoover, H. D. Vertical equating using the Rasch model. Journal of Educational Measurement, 1980, 17, 179-193.

Marco, G. L., Petersen, N. S., \& Stewart, E. E. A test of the adequacy of curvilinear score equating models. In D. J. Weiss (Ed.), Proceedings of the 1979 Conference on Computerized Adaptive Testing. Minneapolis: University of Minnesota, Department of Psychology, Psychometric Methods Program, Computerized Adaptive Testing Laboratory, 1980.

McKinley, R. L. A multidimensional extension of the two-parameter logistic latent trait model. Paper presented at the National Council on Measurement in Education annual meeting, Montreal, April 1983.

McKinley, R. L., \& Reckase, M. D. The use of the general Rasch model with multidimentional item response data (Research Report 82-1). University of Missouri-Columbia, Educational Psychology Department, Tailored Testing Laboratory, 1982.

Mittman, A. An empirical study of methods of scaling achievement tests at the elementary grade level. Unpublished doctoral dissertation, University of Iowa, 1958.

Morgan, G. The use of the Rasch latent trait measurement model in the equating of scholastic aptitude tests. Paper presented at the Invitational Seminar on the Improvement of Measurement in Education and Psychology, Melbourne VIC, Australia, 1980.

Norton, D. W. A suggested method for estimating the proportion of a group selecting the correct response to a multiple-choice item by guessing. Unpublished masters thesis, University of Iowa, 1950.

Petersen, N. S., Cook, L. L., \& Stocking, M. L. Scale drift: A comparative study of IRT versus linear equating methods. Journal of Educational Statistics, in press.

Phillips, S. E., \& Anderson, A. E. LOGTRUE: A computer program for test equating with item response theory. Paper presented at the American Educational Research Association annual meeting, Montreal, Apri] 1983.

Rentz, R. R., \& Bashaw, W. L. The national reference scale for reading: An application of the Rasch model. 
Journal of Educational Measurement, 1977, 14, 161180.

Ryan, J. Examples of person-fit analysis. Paper presented at the American Educational Research Association annual meeting, Rasch measurement pre-session, Boston, April 1980.

Slinde, J. A., \& Linn, R. L. An exploration of the adequacy of the Rasch model for the problem of vertical equating. Journal of Educational Measurement, 1978, $15,23-35$.

Slinde, J. A., \& Linn, R. L. A note on vertical equating via the Rasch model for groups of quite different ability and tests of quite different difficulty. Journal of Educational Measurement, 1979, 16, 159-165.

Swaminathan, H., \& Gifford, J. A. Bayesian estimation in the Rasch model. Journal of Educational Statistics, 1982, 7, 175-191.

Thorndike, R. L. Applied Psychometrics. Boston: Houghton-Mifflin, 1982.

Traub, R. E., \& Wolfe, R. G. Latent trait theories and the assessment of educational achievement. Review of Research in Education, 1981, 9, 377-435.

Wingersky, M. S., Barton, M. A., \& Lord, F. M. LOGIST V User's Guide. Princeton NJ: Educational Testing Service, 1982.

Wood, R. L., Wingersky, M. S., \& Lord, F. M. LOGIST: A computer program for estimating examinee ability and item characteristic curve parameters. ( $R \mathrm{e}-$ search Memorandum 76-6). Princeton NJ: Educational Testing Service, 1976.

Wright, B. D. The Rasch model. Paper presented at the American Educational Research Association annual meeting, Rasch measurement pre-session, Boston, April 1980.
Wright, B. D., \& Mead, R. J. BICAL: Calibrating items and scales with the Rasch model (Research Memorandum No. 23). University of Chicago, Department of Education, Statistical Laboratory, 1976.

Wright, B. D., \& Stone, M. H. Best test design: A handbook for Rasch measurement. Palo Alto CA: Scientific Press, 1979.

Yen, W. M. Using simulation results to choose a latent trait model. Applied Psychological Measurement, 1981, $5,245-262$.

\section{Acknowledgments}

The author is grateful to Nancy Cole, Judith Moyer, and the Riverside Publishing Company for providing data for this study and to Arlin Anderson, Jim Keasler, and $J u d y H u$ for developing the necessary computer programs. The article is based on parts of the author's doctoral dissertation conducted at the University of Iowa. The author thanks Leonard Feldt, Robert Forsyth, A. N. Hieronymus, and H. D. Hoover for their supervision and guidance. Appreciation is also extended to anonymous reviewers who provided constructive suggestions for improving the manuscript.

\section{Author's Address}

Send requests for reprints and further information to S. E. Phillips, College of Education, 458 Erickson Hall, Michigan State University, East Lansing MI 48824, U.S.A. 